SCHILLING, Heinz. Early modern european civilization and its political and cultural dynamism. The Menahem Stern Jerusalem Lectures. Líbano: University Press of New England, 2008, 124 p.

\title{
Rui Luis Rodrigues
}

Doutorando em História Social na Faculdade de Filosofia, Letras e Ciências Humanas da Universidade de São Paulo

Heinz Schilling é um dos mais influentes historiadores alemães da atualidade. Nascido em 1942, Schilling doutorou-se em 1971 com uma pesquisa sobre os imigrantes holandeses no século XVI; dez anos depois, defendeu sua livre-docência com um estudo que se tornou seminal para o desenvolvimento da chamada "teoria da confessionalização". ${ }^{1}$ Após atuar como professor-assistente na Universidade de Bielefeld e como professor nas Universidades de Giessen e Osnabrück, Schilling ocupa, desde 1992, a cátedra de História da Primeira Modernidade no Departamento de História da Universidade Humboldt (Berlim). Membro da Academia Europeia desde 2005, Schilling é um dos editores de Archiv für Reformationsgeschichte (Arquivo para a história da Reforma) e destaca-se como um autor prolífico (mais de onze títulos em várias línguas, além da edição ou coedição de 19 coletâneas, entre obras historiográficas e fontes documentais, e cerca de 160 artigos).

Seu livro Early modern european civilization and its political and cultural dynamism, escrito diretamente em língua inglesa, apresenta-nos as palestras proferidas por Schilling em Jerusalém, nos dias 8, 9 e 11 de maio de 2006, no contexto das "Menahem Stern Lectures" promovidas pela Sociedade Histórica de

\footnotetext{
Essa teoria surgiu no âmbito da história social alemã como uma tentativa de resgatar o lugar dos fenômenos religiosos enquanto objetos válidos para a pesquisa histórica. Preocupou-se especialmente com a compreensão dos processos em que se estruturaram, a partir das reformas religiosas do século XVI, as principais igrejas cristãs, incluindo o catolicismo tridentino, e com as relações entre esses processos e o desenvolvimento de estruturas sociais "modernas", como o Estado burocratizado e os mecanismos de controle social.
} 
Israel. Por se tratar de um texto com características e limites bem marcados - $\mathrm{o}$ tom das palestras foi em geral mantido na versão escrita - o autor obrigou-se a um tratamento mais sintético dos problemas, ao mesmo tempo em que procurou, constantemente, estabelecer relações entre os temas abordados e tópicos hodiernos. Percebe-se, também, no texto, a intenção do autor de responder a algumas das principais críticas que sua teoria tem recebido nos últimos anos.

No primeiro capítulo ("The history of Europe between national and global challenge", p. 1-10), Schilling especifica seus objetivos e delineia os percursos a serem desdobrados no restante da obra. Sua preocupação fundamental está em entender as estruturas-chave e os mecanismos que capacitaram a Europa a embarcar em processos fundamentais de mudança entre o final da Idade Média e os inícios da modernidade; para atingir esse objetivo, ele defende a adoção de um novo paradigma de análise histórica que leve em conta tanto as realidades "nacionais" (mas sem os reducionismos da antiga historiografia política) quanto os aspectos "globais" (mas evitando as chaves de leitura que privilegiam as interferências europeias na história de outras civilizações). Bem de acordo com a práxis historiográfica alemã, Schilling busca o suporte de uma teoria sociológica para sua empreitada. Ele encontra esse apoio no trabalho do sociólogo Shmuel Eisenstadt e, em especial, no seu conceito de "tipos de civilização mundial”. De acordo com Schilling, esse paradigma permitiria a identificação de dois tipos de civilização no contexto europeu: a civilização "latino-europeia" e a "Europa grego-ortodoxa" (p. 8), ambos sensivelmente diferentes. Dentre as características do "tipo latino-europeu" de civilização, Schilling destaca, principalmente, a importância dos conceitos de "lei" e "justiça", derivados do direito romano e da tradição do direito canônico, e o respeito dualístico perante o sacro e o secular (respeito que, segundo Schilling, desde o princípio, dispôs, nas sociedades ocidentais, uma tendência à secularização e impediu que o Ocidente fosse marcado por uma estrutura monística como aquela do Império Romano do Oriente). Operando numa moldura temporal que, em seu arco mais amplo, se estende aproximadamente de 1350 a 1750 , essas características teriam propiciado à civilização latino-europeia seu "específico e aparentemente único dinamismo" (p. 9), a capacidade europeia para a mudança. A tese de Schilling é a de que a Europa ganhou seu decisivo dinamismo em torno de 1600 não a despeito do caos religioso introduzido pelas reformas, mas através da estreita aliança que efetuou com o processo de confessionalização.

É o desenvolvimento dessa tese que encontramos no segundo capítulo ("The confessionalization of european churches and societies - an engine for modernizing and for social and cultural change", p. 11-32). Baseado na noção de "tipos 
de civilização", Schilling pretende mostrar que as pré-condições indispensáveis para que a Europa embarcasse no caminho da modernização ocorreram não por oposição às forças da confessionalização, mas num processo "dialético" no qual elementos novos se mostraram profundamente ligados e entretecidos a essas forças. A razão para isso estaria no dualismo entre sagrado e secular que caracterizaria a Europa latina e no qual ambos permanecem unidos, mas respeitando esferas específicas de responsabilidade. Nessa dinâmica, os processos confessionais teriam colaborado diretamente com o processo de "modernização" da sociedade europeia, na medida em que todos eles geraram "novas Igrejas" portadoras de características distintivamente "modernas" (o que valeria mesmo para o catolicismo tridentino). Embaladas pelo elemento religioso, as sociedades europeias teriam obtido suas configurações distintivamente modernas: os processos confessionais acabaram por reforçar certas características regionais, influenciando a formação de identidades políticas e a própria consolidação do Estado, e facilitando a implantação de disciplinas sociais e seus respectivos mecanismos de controle. Esses processos confessionais foram superados a partir de meados do século XVII, tanto por grupos dissidentes extraconfissões como pelo surgimento de uma ampla diversidade no interior das próprias igrejas confessionais; a possibilidade desses elementos sinaliza a presença, no contexto europeu, da velha tendência à secularização (daí porque, para Schilling, é fundamental compreendê-la sempre em relação dialética com os processos confessionais).

No terceiro capítulo ("Migrations and minorities", p. 33-63), Schilling pretende estudar as contribuições prestadas pelas migrações confessionais para a formação da modernidade (e, em especial, para o delineamento de seu dinamismo econômico). Para tanto, ele não apenas cria o conceito de Konfessionsmigration (p. 38) como defende que essas migrações possuem especificidades que as distinguem de outras formas corriqueiras de migração. Schilling concentra-se na análise, em perspectiva comparada, das duas principais correntes da primeira onda migratória: o ramo dos protestantes refugiados dos Países Baixos (a partir de 1530, com clímax entre 1567 e 1590), e o ramo dos judeus sefarditas oriundos da Península Ibérica ao longo de todo o século XVI.

Na porção mais relevante do capítulo, Schilling procura mostrar como as migrações confessionais se encaixam na "dialética" das mudanças no decorrer da primeira modernidade. Em suma, tanto o tradicionalismo dos grupos confessionais quanto a própria dinâmica confessional, igualmente "pré-moderna", não impediram que essas migrações se tornassem "portadoras de modernidade". Schilling exemplifica isso ao analisar os impulsos ao desenvolvimento econômico e social dados pelas minorias calvinistas na região do Baixo Reno e a relação 
desses impulsos com a identidade religiosa e social desses grupos e, especialmente, com seu status como grupos minoritários. A esses impulsos modernizadores oriundos dos grupos calvinistas Schilling iguala aqueles advindos das comunidades de judeus sefarditas. A tese de Schilling relativiza, assim, a formulação tradicional de Max Weber, ao ver, no ambiente das migrações confessionais e não na "ética protestante" e sua ascese intramundana, o impulso decisivo para esse desenvolvimento econômico.

No último capítulo ("The European crisis of the early seventeenth century and the birth of an international state system”, p. 65-86), Schilling pretende retomar o assunto das relações entre religião e a formação do Estado moderno para iluminar o que the parece um aspecto bastante ignorado do problema: o impacto da confessionalização na formação do moderno sistema de relações internacionais. Seu objetivo é mostrar que a combinação entre religião e política proveu um impulso decisivo para uma mudança fundamental na estrutura e no funcionamento da política internacional (p. 67-8), de forma que, após os tratados que encerraram as lutas confessionais em meados do século XVII, o universalismo e gradualismo medievais acabaram definitivamente substituídos por um sistema de estado moderno, secular e pluralístico. Esse sistema moderno teria emergido de uma crise intensa ocorrida no início do século XVII e que deu absoluta primazia aos assuntos confessionais. A priorização do aspecto religioso-dogmático é descrita por Schilling através do conceito de "fundamentalismo confessional" (p. 77); esse fenômeno, que explicaria o terrível conflito que foi a Guerra dos Trinta Anos, foi superado pela ação conjunta de dois fatores: a permanência de uma forte tradição legal no Ocidente e o fato de que essa tradição legal contava também com uma legitimação de natureza religiosa. Esse reconhecimento da legitimidade da tradição legal pela religião se deveu, essencialmente, à preservação do antigo dualismo entre religião e autoridade civil; em suma, o "fundamentalismo confessional" pôde ser superado porque, de fato, nunca conseguira suplantar a tradição dualista. Inerente ao dualismo da cristandade europeia, portanto, o papel da secularização teria sido fundamental para a superação dos conflitos confessionais, dando início, segundo Schilling, a um período caracterizado por "guerras de aliança" no qual a força militar teria sido utilizada dentro de uma racionalidade distintivamente moderna.

O texto claro e elegante de Heinz Schilling merece elogios: seu estilo é agradável e nem mesmo a invejável erudição de seu autor consegue torná-lo pesado. As tentativas de relacionar os temas da pesquisa histórica a problemas contemporâneos se explicam pela origem do texto, contribuindo, sem dúvida, para torná-lo atraente e dinâmico. 
A preocupação com a ideia de "modernização" marca o livro de Schilling. Para o historiador alemão, o "dinamismo político e cultural" da civilização europeia encontra-se sobretudo em sua capacidade de gerar mudanças sociais fundamentais (p. 7). Essa fixação num processo de modernização para o qual a confessionalização teria contribuído foi um dos aspectos mais criticados dessa teoria nos últimos anos, especialmente em função de seu caráter implicitamente teleológico. A introdução de uma abordagem inspirada nas teorias sociológicas de Shmuel Einsenstadt procurou superar algumas dessas críticas; afinal, o modelo de Eisenstadt valoriza a comparação entre civilizações, ao invés de superestimar o papel "modernizador" das sociedades europeias, e trabalha com a noção de "múltiplas modernidades" assinaladas não pela uniformidade ou homogeneidade, mas pela diversidade. No entanto, apesar dos esforços de Schilling, persiste no texto um viés teleológico; doutra forma, como entender sua observação de que as divisões religiosas do século XVI devem ser compreendidas em sua conotação positiva, como fatores de diferenciação teológica responsáveis por trazer o "mundo cristão" da "monocultura eclesiástica" da Idade Média para o pluralismo religioso e social da atualidade (p. 17-8)? Obviamente, essa leitura da "positividade" do cisma, além de valorativa e carregada de conotações ideológicas, só faz sentido enquanto leitura retrospectiva do fenômeno histórico. A nós, historiadores, cabe procurar descrever esses fenômenos e analisá-los na esperança de entender como os agentes históricos se posicionaram diante deles - e dificilmente essa conotação positiva teria sido percebida naquele contexto.

Isto nos conduz a outro aspecto na abordagem de Schilling que merece crítica: sua excessiva dependência de esquemas teóricos oriundos da sociologia. A história social alemã, aliás, apresenta tradicionalmente essa tendência e pretende derivar dela um maior grau de cientificidade. Nos historiadores ligados à teoria da confessionalização predomina esse interesse por encontrar explicações no nível "macro"; daí o apego às interpretações estruturais, de longa duração e sempre de viés fortemente teorético, como acontece com as noções de um processo "modernizador" ou "secularizador". Mas esse aspecto assume, no presente trabalho, um caráter mais grave por conta da ambição de Schilling de definir uma "abordagem científica" para a história que, no limite, permitiria responder à acusação, frequentemente lançada contra ela, de relativismo (p. 7-8). Não apenas a excessiva dependência de formulações teóricas apresenta o risco de afastar a pesquisa histórica da empiria, tornando-a por demais abstrata; essa busca pela "cientificidade" no campo da história tem os contornos de um canto de sereia eivado de ideologia. 
Com relação às "migrações confessionais", é fato já largamente assinalado pela historiografia que elas desempenharam um papel importante no desenvolvimento das sociedades hospedeiras. Todavia, o que precisa ser questionado é se esse impulso provocado pelas migrações deve tanto quanto Schilling supõe ao seu caráter "confessional". Para o autor, a confessionalização, operando tanto nas comunidades de imigrantes quanto no entorno social, constituiu-se na pré-condição para seu excepcional dinamismo; podemos considerar, em contrapartida, que o elemento confessional apenas provocou as migrações ou reforçou a exclusão dos grupos minoritários da vida social, fazendo com que estes desenvolvessem suas atividades econômicas à parte das antigas estruturas de guildas e se tornassem mais envolvidos com seus empreendimentos ao se verem alijados da vida pública. Mas neste caso, a contribuição da confessionalização foi sempre indireta; não se pode vê-la como causa direta do dinamismo econômico, mas apenas como um dos fatores que integram o quadro, complexo, que produziu esse dinamismo. Indo além, podemos recordar que Hugh R. Trevor-Roper já assinalara a importância das migrações flamengas para o desenvolvimento econômico dos mesmos centros urbanos apontados por Schilling, ${ }^{2}$ para o historiador britânico, contudo, a razão fundamental das migrações repousou não na questão confessional, mas na "razão de Estado da Contrarreforma" com sua constituição de uma "sociedade de funcionários", numa dinâmica que se revelou limitadora e desinteressante para a prática industrial e comercial. ${ }^{3}$

Ao discutir, no último capítulo, a superação efetiva da atitude confessional e a formação, em meados do século XVII, de um sistema internacional de estados, Schilling frisa a importância do papel desempenhado pelos pilares "lei" e "religião" (p. 80); foi a estrutura dualística que permitiu às autoridades civis, quando necessário, proceder à revelia dos interesses confessionais (p. 81-2). Neste campo, a primeira crítica poderia ser dirigida ao próprio conceito de "fundamentalismo confessional". Conceito com origem bastante específica, foi somente por empréstimo que o termo "fundamentalismo" passou a descrever atitudes estreitas em religião, independentemente do credo. Nenhuma razão, no

2 TREVOR-ROPER, H. R. Religião, reforma e transformação social. In: Idem. Religião, reforma e transformação social. Tradução portuguesa. Lisboa: Presença, 1981, p. 13-42.

3 TREVOR-ROPER, H. R., op. cit., p. 41, 37. Não cabe aqui, obviamente, uma discussão do viés ideológico contido na hipótese de Trevor-Roper; mas não pode passar despercebido o fato de Schilling não ter feito qualquer referência a essa formulação. Aliás, Schilling também não menciona Werner Sombart que, já em 1902, apontava para a importância das migrações de judeus sefarditas no século XVI como elemento dinamizador da economia europeia (ver a propósito TREVOR-ROPER, op. cit., p. 15-6). 
entanto, justificaria o uso do vocábulo para descrever a atitude predominante nos grupos confessionais durante a primeira modernidade. Se nos ativermos ao uso contemporâneo do termo, como Schilling parece fazer (o texto não faz qualquer menção ao contexto de surgimento da palavra "fundamentalismo"), então este se torna ainda mais inadequado: a atitude fundamentalista parece exigir uma concepção monista de sociedade, como ocorre nas teocracias islâmicas, e, nesse caso, a alegada permanência do dualismo na sociedade europeia durante o período confessional inviabilizaria o conceito proposto por Schilling.

Minha última crítica se dirige à maneira como Schilling entende a superação desse ambiente "fundamentalista" na primeira modernidade. Se a questão se resolveu de maneira decisiva pela permanência da estrutura dualística, como Schilling sugere, então não foi a confessionalização que exerceu qualquer papel determinante, mas essa tendência latente à secularização. Schilling procura encarecer o fato de que o processo de confessionalização não foi superado por um movimento contrário à religião, mas por um processo que operou conjuntamente com ela. Todavia, como ele admite, a solução veio de fora da religião, pois se originou numa configuração específica da cristandade latina (p. 85). Que esse processo de superação da atitude confessional não tenha sido marcado por irreligiosidade, é algo óbvio; todavia, afirmar que o papel preponderante pertenceu aos processos confessionais representa, mais do que um grande exagero, uma severa distorção.

Enquanto fenômeno histórico, a confessionalização - ou seja, os contextos, mecanismos e processos nos quais e pelos quais os grupos religiosos oriundos da cristandade dividida se estruturaram, dando expressão específica às suas identidades religiosas e determinando, inevitavelmente, mudanças significativas nas estruturas sociais - continua sendo um objeto relevante de estudo, sem o qual a compreensão da primeira modernidade seria impossível. Afirmar a validade desse objeto para a história social, todavia, não depende de atribuirmos a ele qualquer papel como agente de mudanças ou estimulador de tendências modernizadoras. No meu entender, seria mais apropriado ler o fenômeno confessional como a grande reação que, no desejo de retornar ao universalismo perdido, pôs em risco o próprio dualismo da civilização latino-europeia. Em seu belo e apaixonante livro, Heinz Schilling oferece várias provas da competência que fez dele um dos maiores historiadores europeus de nossos dias; mas, ao mesmo tempo, esse texto documenta sua decisão de permanecer amarrado ao mastro de um barco teórico que começa a fazer água.

Recebido: 07/05/2010 - Aprovado: 02/09/2011. 